\title{
KAJIAN PROYEKSI PEMENUHAN KEBUTUHAN ENERGI PROVINSI KEPULAUAN RIAU
}

\author{
Ihsan Saputra*, Didi Istardi\#, Muslim Ansori ${ }^{\circledR}$, Cahyo Budi Nugroho*, Abulija Maskarai* \\ Politeknik Negeri Batam \\ *Mechanical Engineering study Program \\ \#Electrical Engineering Study Program \\ ${ }^{\circledR}$ Business Management study Program \\ Parkway Street, Batam Centre, Batam 29461, Indonesia \\ E-mail: ihsan@polibatam.ac.id
}

\begin{abstract}
Abstrak
Energi memiliki peranan penting dalam perkembangan pertumbuhan ekonomi dan pertumbuhan industri baik jangka panjang maupun jangka pendek. Dengan tingkat pertumbuhan ekonomi 5,02\% dan tingkat pertumbuhan penduduk 1,79\% tiap tahun di Provinsi Kepulauan Riau, perlu direncanakan dengan baik strategi pemenuhan energi. Pada penelitian ini akan dikaji tentang sumber energi dan kebutuhan energi di Provinsi Kepulauan Riau. Selain itu dilakukan pemodelan menggunakan LEAP untuk memprediksi kebutuhan energi hingga tahun 2025 di Provinsi Kepulauan Riau. Dari hasil penelitian didapat kebutuhan energi Kepulauan Riau didominasi oleh kebutuh Natural Gas sebesar 53\% dari total 1,73 Mtoe pada tahun 2015 dan sektor pengguna paling besar adalah sektor rumah tangga dan industri. Selain itu dari hasil proyeksi penggunaan energi, tahun 2025 energi paling besar di konsumsi adalah Natural gas sebesar 0,98 Mtoe dari total 2,4 Mtoe dan sektor pengguna paling besar adalah sektor industri. Produksi Natural gas dan minyak bumi provinsi kepulauan riau menurun tiap tahunnya sehingga perlu dilakukan diversifikasi energi untuk pemenuhan kebutuhan energi di Provinsi Kepulauan Riau.
\end{abstract}

Kata kunci : Sankey diagram, LEAP model, Energy flow, Energy use, Kepulauan Riau

\begin{abstract}
Energy has an important role in the development of economic growth and industrial growth both long term and short term. With an economic growth rate of $5.02 \%$ and a population growth rate of $1.79 \%$ each year in Provinsi Kepulauan Riau, it is necessary to plan for energy strategy. In this study will be studied about energy supply and energy demand in Provinsi Kepulauan Riau. Energy modeling is done using LEAP to predict energy needs until 2025 in Provinsi Kepulauan Riau. From the results of the study, it was found that Provinsi Kepulauan Riau' energy demand were dominated by Natural Gas needs of 53\% of the total 1.73 Mtoe in 2015 and the largest user sector was the household and industrial sectors. In addition from the projection of energy use, the largest energy consumption in 2025 is Natural gas of 0.98 Mtoe from a total of 2.4 Mtoe and the largest user sector is the industrial sector. Production of natural gas and petroleum in Provinsi Kepulauan Riau decreases each year so that energy diversification is needed to meet energy needs in Provinsi Kepulauan Riau.
\end{abstract}

Keywords : Sankey diagram, LEAP model, Energy flow, Energy use, Kepulauan Riau

\section{PENDAHULUAN}

Energi memiliki peranan penting dalam perkembangan pertumbuhan ekonomi dan pertumbuhan industri baik jangka panjang maupun jangka pendek. Jika pengelolaan dan strategi pemenuhan energi kurang tepat akan menyebabkan krisis energi. Sebagai salah satu provinsi di Indonesia, Kepulauan Riau memiliki lokasi strategis karena terletak pada jalur perdagangan yang berbatasan dengan Singapura, Laut Cina Selatan, Selat Malaka, dan Selat Karimata. Dimana Luas area Provinsi Kepulauan Riau yaitu $252.601 \mathrm{~km}^{2}$. Wilayah Kepulauan Riau terdiri dari 5 Kabupaten dan 2 Kota, 42 Kecamatan, serta 256 Kelurahan/Desa dengan jumlah 2.408 pulau besar dan kecil dimana $40 \%$ belum bernama dan 
berpenduduk dengan tingkat pertumbuhan ekonomi 5,02\% [1],[2]. Tingkat pertumbuhan ekonomi mendorong peningkatan pertumbuhan penduduk yang sangat pesat di Provinsi Kepulauan Riau. Hal ini tentu menjadi permasalahan terutama dalam pemenuhan kebutuhan energi di Provinsi Kepulauan Riau.

Pemetaan Energi bukan hal baru lagi dan telah dilakukan banyak penelitian di beberapa negara. Untuk memetakan aliran energi umumnya digunakan sankey diagram dimana berfungsi untuk memetakan aliran energi dari sumber energi ke pemakaiannya. Seperti yang dilakukan (schmidt, 2008) untuk memetakan aliran dan manajemen material [3]. Selain schmidt, Veena subramanya, 2015 juga menggunakan sankey diagram untuk memetakan energi dari sumber energi utama ke pengguna [4]. Studi lain terkait pemetaan energi dilakukan oleh chinhao chong, 2015 untuk memetakan penggunaan energi di malaysia [5]. Linwei ma, 2002 memetakan energi menggunakan metode pemetaan keseimbangan total exergy input dan output metric [6]. Pada penelitian yang dilakukan sebelumnya, energi dibedakan menjadi energi terbarukan dan tidak terbarukan, dan pengguna di bagi menjadi empat sektor yaitu sektor transportasi, rumah tangga, industri, dan komersial.

Kajian pemenuhan kebutuhan energi provinsi kepulauan riau ini bertujuan untuk memetakan kebutuhan energi dari sektor pengguna dan memprediksi kebutuhan energi sampai lima tahun kedepan. Selain itu manfaat kajian ini adalah untuk dasar pembuatan kebijakan oleh pemerintah provinsi kepulauan riau dalam menyusun kebijakan penggunaan energi.

\section{METODE PENELITIAN}

\section{a. LEAP Model}

Pada studi ini long range energy alternative planning system (LEAP) model digunakan untuk memetakan sumber energi primer, energi sekunder, dan sektor pemanfaatannya. Dari hasil pemetaan dianalisa keseimbangan energi dari sektor sumber energi dan sektor pemanfaatannya. Selain itu, menggunakan model LEAP kebutuhan energi tiap sektor sampai lima tahun kedepan dapat diprediksi. Pada pemodelan ini sektor pemanfaatan dibagi menjadi empat sektor yaitu sektor rumah tangga, sektor transportasi, sektor industri, dan sektor komersial. Adapun alur skematis diagram pemodelan pada LEAP ditampilkan sebagai berikut.

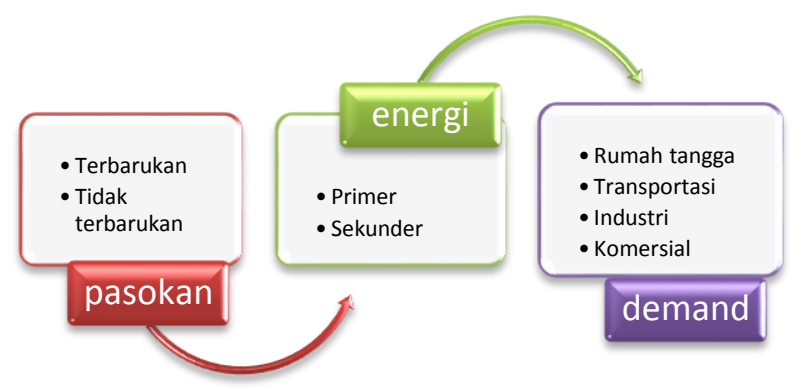

Gambar.1 Skematis diagram alur pemodelan menggunakan LEAP.

Pada kajian ini akan dijelaskan satu persatu diagram untuk sektor sumber energi dan sektor pemanfaatan. Adapun pembagian sumber energi berdasarkan jenisnya ditampilkan sebagai berikut.

\begin{tabular}{ll}
\hline \multicolumn{1}{c}{ Tipe energi } & Jenis energi \\
\hline a. Energi Primer & Minyak bumi \\
a.1. Energi tidak terbarukan & Batu Bara \\
& Gas Bumi \\
& LPG \\
& Panas bumi \\
& Angin \\
a.2. Energi baru terbarukan & Air \\
& Surya \\
& Biomass \\
b. Energi Sekunder & CNG \\
& LNG \\
& Listrik \\
\hline
\end{tabular}

Sumber energi primer yang dikonversi menjadi sumber energi lain dikategorikan sebagai energi sekunder. Seperti disebutkan sebelumnya energi sekunder contohnya adalah CNG, LNG, dan Listrik. Dari sisi sektor pemanfaatan energi dikategorikan menjadi empat sektor yaitu sektor industri, komersial, rumah tangga, dan sektor transportasi. Penggolongan masing-masing sektor ditampilkan pada tabel berikut.

\begin{tabular}{ll}
\hline $\begin{array}{c}\text { Sektor } \\
\text { pemamfaatan }\end{array}$ & \multicolumn{1}{c}{ Jenis pemamfaatan } \\
\hline Industri & $\begin{array}{l}\text { Industri manufaktur, galangan, } \\
\text { industri metal, industri plastik dll }\end{array}$ \\
Komersial & $\begin{array}{l}\text { Hotel, Fasilitas publik, dan gedung } \\
\text { pemerintahan. }\end{array}$ \\
Rumah Tangga & $\begin{array}{l}\text { Untuk memasak, penerangan, Air } \\
\text { conditioner, dll } \\
\text { Transportasi Darat }\end{array}$ \\
Transportasi & $\begin{array}{l}\text { Transportasi Laut } \\
\text { Transportasi Udara }\end{array}$ \\
\hline
\end{tabular}

b. Asumsi yang digunakan pada pemodelan

Pada kajian ini ini data yang digunakan untuk pemodelan LEAP berupa data sekunder seperti data yang diambil dari data BPS (badan pusat statistik) Provinsi Kepulauan Riau, data dari badan pusat statistik Kabupaten/kota di Provinsi Kepulauan 
Riau, data dari Dinas ESDM, dan data dari BAPPEDA. Untuk sektor industri diasumsikan untuk industri sejenis mengkonsumsi energi dalam jumlah yang sama. Selain itu trend pertumbuhan ekonomi diasumsikan linear dan sama tiap tahunnya yaitu $5,02 \%$.

Untuk sektor rumah tangga, transportasi, dan komersial, tingkat pertumbuhan penduduk diasumsikan trend pertumbuhannya linear tiap tahun dari tahun 2010 sampai 2018 yaitu 1,79\% dan tingkat pertumbuhan ini digunakan untuk memprediksi kebutuhan energi sampai tahun 2025.

Untuk data sektor energi sekunder yaitu energi yang digunakan untuk menghasilkan jenis energi lain yang digunakan oleh sektor pemanfaatan didapat dari data sekunder Pembangkit Listrik Nasional (PLN) dan beberapa sektor pembangkit swasta, badan usaha, dan pihak terkait seperti ESDM, BPS, dan BAPPEDA .

Dari sisi pemenuhan pasokan (supply) energi didapat dari jumlah energi yang dihasilkan oleh Provinsi Kepulauan Riau sendiri dan dari luar Provinsi Kepulauan Riau. Untuk pasokan energi diasumsikan jumlahnya sama dengan kebutuhan (demand) energi Provinsi Kepulauan Riau.

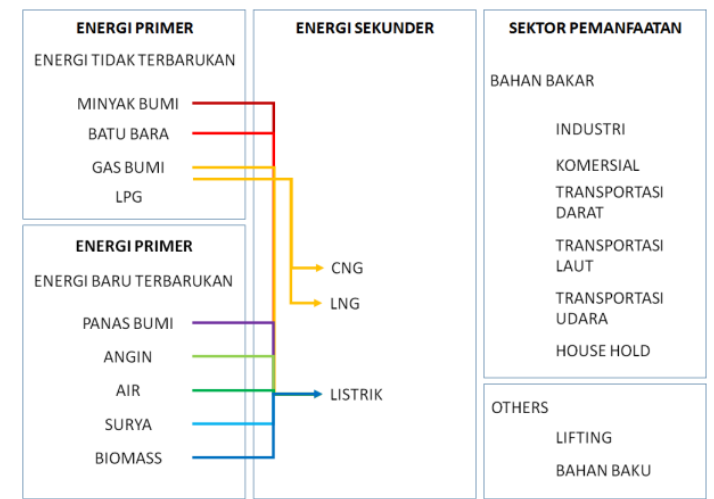

Gambar.2 Kerangka Pemodelan pemenuhan kebutuhan energi Provinsi Kepulauan Riau.

\section{HASIL DAN PEMBAHASAN}

a. Tingkat pertumbuhan penduduk Provinsi Kepulauan Riau.

Penduduk dalam pembangunan mempunyai peran sebagai pelaku (subjek) dan juga sebagai tujuan (objek). Penduduk sangat mempengaruhi dinamika pembangunan, jumlah penduduk yang besar diikuti dengan kualitas penduduk yang memadai, akan merupakan pendorong bagi pertumbuhan ekonomi. Oleh karenanya pembangunan kependudukan memiliki peran yang sangat penting dalam pencapaian tujuan pembangunan, terutama dalam upaya peningkatan kualitas sumber daya manusia. Masalah utama kependudukan di Provinsi Kepulauan Riau adalah: laju pertumbuhan yang tinggi, penyebaran yang tidak merata, dan migrasi penduduk yang masuk cukup Besar. Tingkat pertumbuhan rata-rata penduduk Provinsi Kepulauan Riau adalah 1,79\%. Laju pertumbuhan penduduk yang paling besar terjadi di kota Batam yaitu dengan tingkat pertumbuhan $4,72 \%$. Tingkat pertumbuhan penduduk untuk masing-masing Kabupaten/Kota di Provinsi Kepulauan Riau dari tahun 2010-2015 yaitu sebagai berikut.

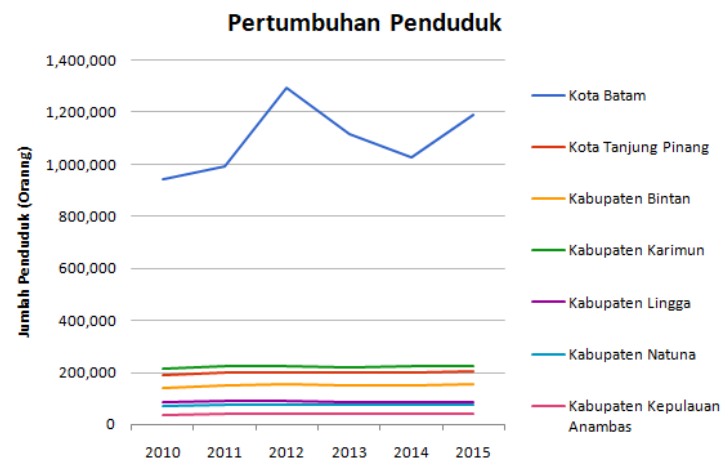

Gambar.3 Tingkat pertumbuhan penduduk Provinsi Kepulauan Riau Tahun 2010-2015

b. Pemetaan pasokan energi

Provinsi kepulauan Riau kaya akan gas dan minyak bumi. Namun, dari data Dinas Energi dan Sumberdaya Mineral Provinsi Kepulauan Riau produksi minyak bumi dan gas menurun tiap tahunnya (Gambar.4). Tahun 2013, produksi minyak bumi Provinsi Kepulauan Riau mencapai 13.860 ribu barrel, selanjutnya ditahun 2014 dan 2015 produksi minyak bumi Provinsi Kepulauan Riau menurun menjadi 12.236 ribu barrel dan 10.179 ribu barrel. Produksi energi Provinsi Kepulauan Riau ini digunakan untuk pemenuhan kebutuhan sendiri dan untuk ekspor.

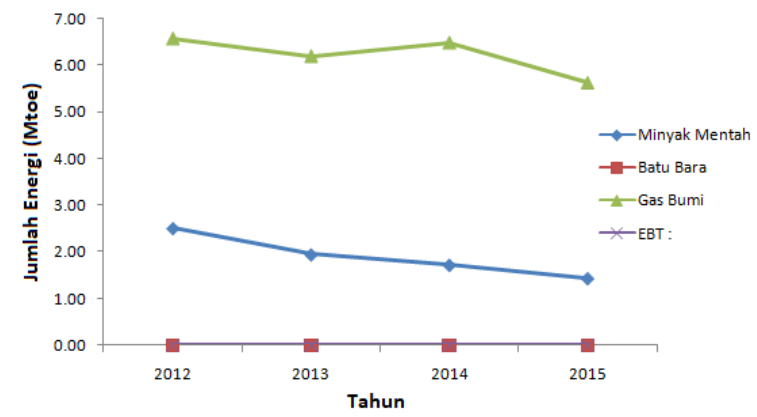

Gambar.4 Produksi Energi Provinsi Kepulauan Riau tahun 2012-2015

Tabel.1 Produksi Energi Provinsi Kepulauan Riau tahun

\begin{tabular}{ccccc}
\multicolumn{5}{c}{ 2012-2015 (Mtoe) } \\
\hline Jenis & $\mathbf{2 0 1 2}$ & $\mathbf{2 0 1 3}$ & $\mathbf{2 0 1 4}$ & $\mathbf{2 0 1 5}$ \\
\hline Minyak Mentah & 2.51 & 1.94 & 1.71 & 1.43 \\
Batu Bara & 0.00 & 0.00 & 0.00 & 0.00 \\
Gas Bumi & 6.58 & 6.20 & 6.49 & 5.63 \\
EBT : & 0.00 & 0.00 & 0.00 & 0.00 \\
Total & $\mathbf{9 . 0 9}$ & $\mathbf{8 . 1 4}$ & $\mathbf{8 . 2 0}$ & $\mathbf{7 . 0 5}$ \\
\hline
\end{tabular}

c. Pemetaan kebutuhan energi persektoral

Kebutuhan energi meningkat tiap tahunnya terutama untuk sektor rumah tangga. Dengan meningkatnya pertumbuhan ekonomi $(5,02 \%)$ di 
Provinsi Kepulauan Riau, mendorong pertumbuhan penduduk yang sangat pesat. Konsumsi energi sektor rumah tangga tahun 2015 sebesar $29 \%$. Konsumsi Energi rumah tangga ini berupa minyak tanah dan LPG dimana kebutuhan terhadap LPG meningkat tiap tahunnya.

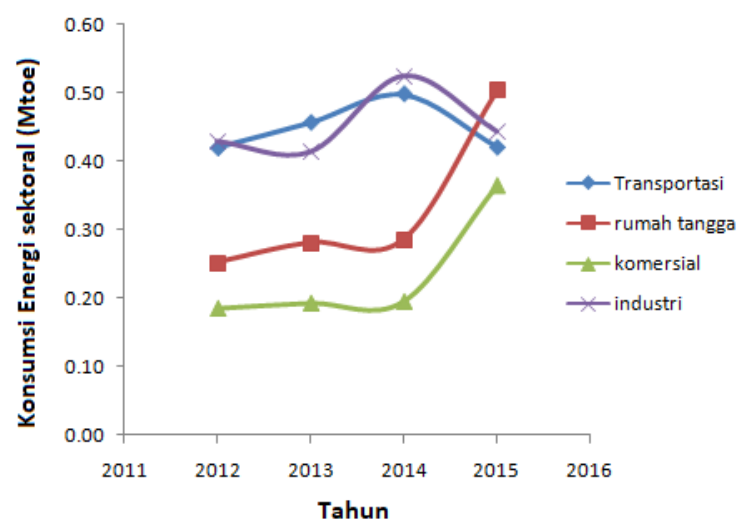

Gambar.5 Pemetaan kebutuhan energi sektoral tahun 2012-2015 di Provinsi Kepulauan Riau

Tabel.2 Kebutuhan Energi per sektoral Provinsi Kepulauan Riau tahun 2012-2015 (Mtoe).

\begin{tabular}{ccccc}
\hline Sektor & $\mathbf{2 0 1 2}$ & $\mathbf{2 0 1 3}$ & $\mathbf{2 0 1 4}$ & $\mathbf{2 0 1 5}$ \\
\hline Transportasi & 0.42 & 0.46 & 0.50 & 0.42 \\
rumah tangga & 0.25 & 0.28 & 0.29 & 0.50 \\
komersial & 0.19 & 0.19 & 0.20 & 0.36 \\
industri & 0.43 & 0.41 & 0.52 & 0.44 \\
\hline Total & $\mathbf{1 . 2 9}$ & $\mathbf{1 . 3 4}$ & $\mathbf{1 . 5 0}$ & $\mathbf{1 . 7 3}$ \\
\hline
\end{tabular}

Dari Tabel.2 didapat laju pertumbuhan konsumsi energi untuk sektor transportasi sebesar 3,8\% pada tahun 2012-2014 sedangkan pada tahun 2015 terjadi penurunan konsumsi energi untuk sektor transportasi sebesar 7,2\%. Hal ini disebabkan kondisi perekonomian Provinsi Kepulauan Riau bergantung pada perekonomian global dimana perekonomian global sedang turun pada tahun 2015 .

Untuk sektor rumah tangga tingkat pertumbuhan konsumsi energi dari tahun 2012-2015 adalah $7,5 \%$, sedangkan tingkat pertumbuhan konsumsi energi untuk sektor komersial dan sektor industri bertambah sebesar 5,4\% dan 1,5\%.

\section{Profil demand energi sektoral}

2015

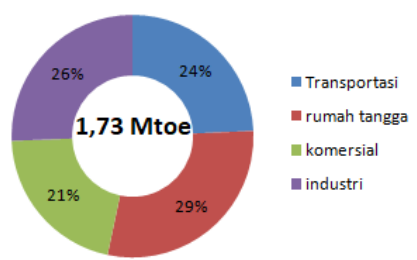

Gambar.6 Profil kebutuhan energi persektoral tahun 2015 di Provinsi Kepulauan Riau

Profil kebutuhan energi persektoral jika dituangkan dalam bentuk profil menurut kategori jenis mineral didapat bahwa Provinsi Kepulauan
Riau mengkonsumsi energi paling besar di tahun 2015 berupa gas bumi sebesar 53\%, selanjutnya konsumsi BBM dan Batu bara.

\section{Demand Energi Kepri 2015}

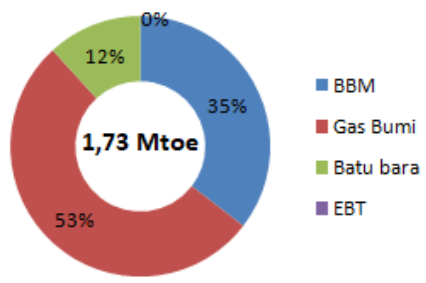

Gambar.7 Profil kebutuhan energi berdasarkan jenis energi tahun 2015 di Provinsi Kepulauan Riau

d. Analisa pemenuhan energi

Pemenuhan kebutuhan energi mempertimbangkan sisi pasokan (supply) energi yang tersedia dan kebutuhan (demand) energi. Provinsi Kepulauan Riau menghasilkan Gas dan Minyak Bumi, tapi tidak menghasilkan batu bara dan hanya sedikit menghasilkan EBT. Untuk pemenuhan kebutuhan energi selain gas dan minyak bumi didapat dari luar Provinsi Kepulauan Riau.

Hasil pemetaan bauran energi baik dari sisi pasokan maupun sisi kebutuhan ditampilkan dalam bentuk sankey diagram sebagai berikut.

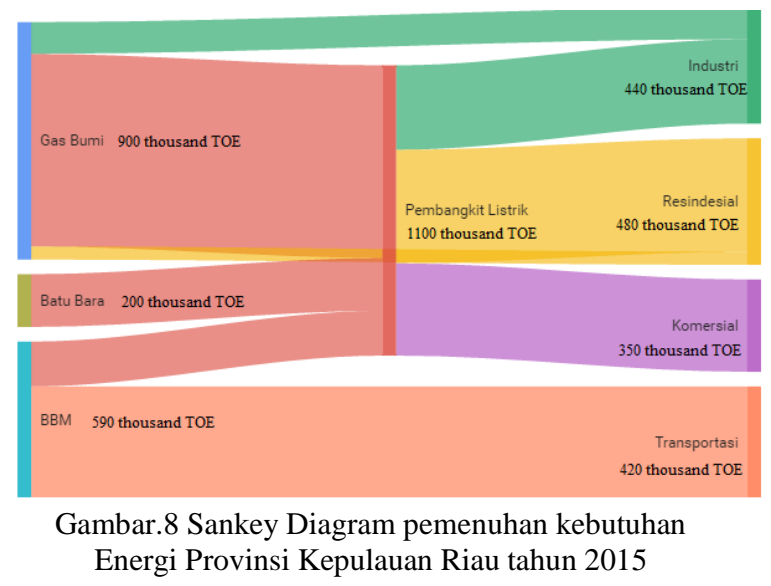

Tahun 2015, kebutuhan energi paling besar dari sisi sektoral adalah sektor rumah tangga sebesar 0,48 Mtoe sedangkan dari sisi pasokan kebutuhan energi paling besar adalah energi gas bumi sebesar 0,9 Mtoe.

Dengan menggunakan data trend pertumbuhan penduduk $1,79 \%$, data trend pertumbuhan ekonomi $5,02 \%$, dan data pendukung lainnya, tingkat pertumbuhan konsumsi energi Provinsi Kepulauan Riau dapat diprediksi hingga tahun 2025. Adapun hasil pemodelan LEAP untuk proyeksi kebutuhan energi per sektoral Provinsi Kepulauan Riau hingga tahun 2025 ditampilkan sebagai berikut. 


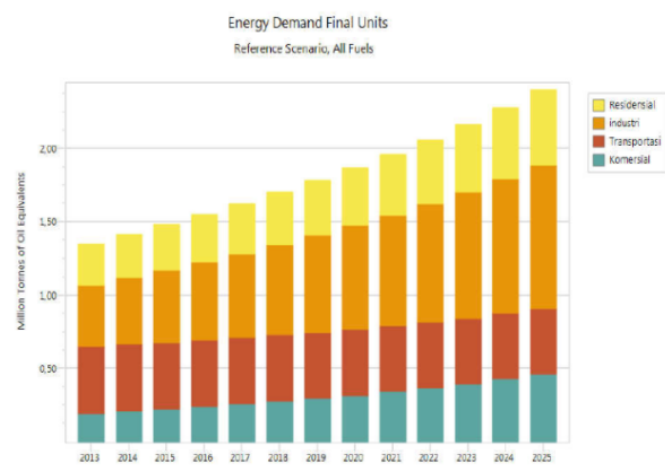

Gambar.9 Hasil proyeksi pasokan energi untuk Provinsi Kepulauan Riau (2014-2025)

Tabel.3 Proyeksi kebutuhan energi Provinsi Kepulauan Riau tahun 2014-2025 (Mtoe)

\begin{tabular}{cccccccccccccc}
\hline Seltor & 2013 & 2014 & 2015 & 2016 & 2017 & 2018 & 2019 & 2020 & 2021 & 2022 & 2023 & 2024 & 2025 \\
\hline Residerzial & 0,28 & 0,30 & 0,31 & 0,33 & 0,34 & 0,36 & 0,38 & 0,39 & 0,41 & 0,44 & 0,46 & 0,49 & 0,51 \\
Indistyy & 0,42 & 0,45 & 0,49 & 0,53 & 0,57 & 0,61 & 0,66 & 0,71 & 0,75 & 0,81 & 0,86 & 0,92 & 0,98 \\
Transpart & 0,46 & 0,45 & 0,45 & 0,45 & 0,45 & 0,45 & 0,45 & 0,45 & 0,45 & 0,45 & 0,45 & 0,45 & 0,44 \\
Commercial & 0,19 & 0,21 & 0,22 & 0,24 & 0,26 & 0,28 & 0,30 & 0,32 & 0,34 & 0,37 & 0,40 & 0,43 & 0,46 \\
\hline Total & $\mathbf{1 , 3 5}$ & $\mathbf{1 , 4 1}$ & $\mathbf{1 , 4 8}$ & $\mathbf{1 , 5 5}$ & $\mathbf{1 , 6 2}$ & $\mathbf{1 , 7 0}$ & $\mathbf{1 , 7 8}$ & $\mathbf{1 , 3 7}$ & $\mathbf{1 , 9 6}$ & $\mathbf{2 , 0 6}$ & $\mathbf{2 , 1 6}$ & $\mathbf{2 , 2 7}$ & $\mathbf{2 , 4 0}$ \\
\hline
\end{tabular}

Tahun 2025 kebutuhan energi Provinsi Kepulauan Riau sebesar 2,40 Mtoe dimana kebutuhan energi paling besar oleh industri sebesar 0,98 Mtoe. Sedangkan sektor rumah tangga sebesar 0,51 Mtoe. Berdasarkan kategori jenis bahan bakar (mineral) proyeksi kebutuhan energi paling besar tahun 2025 adalah bahan bakar Natural Gas sebesar 0,98 Mtoe.

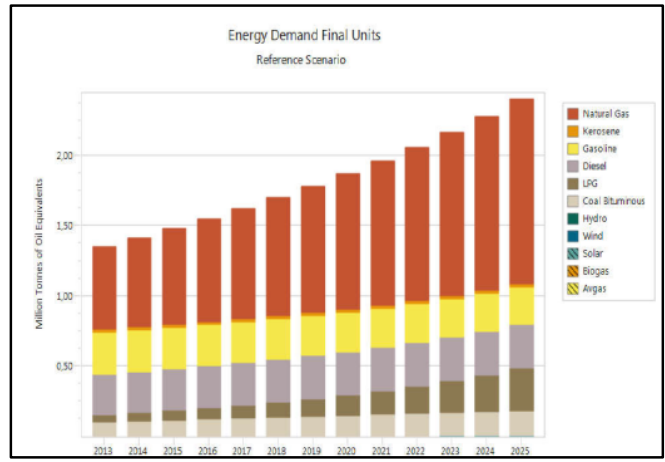

Gambar.10 Proyeksi kebutuhan energi Provinsi

Kepulauan Riau berdasarkan kategori jenis mineral

Isu utama permasalah terhadap bauran energi adalah availability, accessability, affordability, \& sustainability (3A1S). Provinsi Kepulauan Riau merupakan salah satu penghasil gas bumi dan minyak bumi terbesar di Indonesia, ketersediaan gas bumi dan minyak bumi relatif lebih mudah didapatkan daripada batubara dan EBT sehingga untuk primary supply (pasokan utama) Provinsi Kepulauan Riau menggunakan gas bumi dan minyak bumi. Akan tetapi ketersediaan gas bumi dan minyak di Provinsi Kepulauan Riau menurun tiap tahunnya sehingga perlu dilakukan diversifikasi energi terutama beralih ke energi terbarukan. Hingga saat ini jumlah energi terbarukan di Provinsi Kepulauan Riau masih sangat rendah. Bentuk energi terbarukan di Provinsi Kepulauan Riau yang sudah termanfaatkan yaitu Mikrohidro dengan daya 40 $\mathrm{kW}$, panel surya dengan daya $2.846 \mathrm{~kW}$, sedangkan untuk energi gelombang laut, tenaga angin, dan energi pasang-surut belum termanfaatkan dengan maksimal.

\section{KESIMPULAN}

Laju pertumbuhan penduduk Provinsi Kepulauan Riau adalah 1,79\% tiap tahunnya dengan tingkat pertumbuhan ekonomi 5,02\%. Dengan meningkatnya pertumbuhan penduduk dan pertumbuhan ekonomi ini menyebabkan peningkatan konsumsi energi tiap tahunnya. Secara sektoral pertumbuhan konsumsi energi didapat untuk sektor transportasi, rumah tangga, komersial, dan industri adalah sebesar 3,8\%, 7,5\%,5,4\%, dan $1,5 \%$. Sektor paling besar mengkonsumsi energi adalah sektor rumah tangga dan sektor industri yaitu 29\% dan 26\% dari 1,73 Mtoe. Dari hasil proyeksi didapat kebutuhan energi Provinsi Kepulauan Riau pada tahun 2025 sebesar 2,4 Mtoe dengan pengguna paling besar adalah sektor industri sebesar 0,98 Mtoe dan kategori jenis bahan bakar yang paling banyak digunakan adalah Natural gas.

\section{REFERENSI}

[1] Badan Pusat Statistik. Kepulauan Riau dalam angka tahun 2010-2018. https://kepri.bps.go.id/ di akses 6 Februari 2019.

[2] Badan Perencenaan Daerah (BAPPEDA) Provinsi Kepulauan Riau tahun 2010-2018. http://bappeda.kepriprov.go.id/index.php/datainformasi di akses 28 Januari 2019.

[3] Schmidt, Mario. The Sankey Diagram in Energy and Material Flow Management. Journal of Industrial Ecology Vol.12, Number 1 (2008).

[4] Subramanyam, Veena, Deepak Paramshivan, Amit Kumar, Md. Alam Hossain Mondal. Using Sankey Diagrams to Map Energy Flow from Primary Fuel to End Use. Energy Conversion and Management 91 (2015) 342-352.

[5] Chong, Chinhao, Weidou Ni, Linwei Ma, Pei Liu, Zheng Li. The Use of Energy in Malaysia: Tracing Energy Flows from Primary Source to End Use. Energies 2015, 8, 2828-2866. ISSN 19961073.

[6] Ma, Linwei, Julian M.Alwood, Jonathan M. Cullen, Zheng Li. The Use of Energy in China: Tracing the Flow of Energy from Primary Source to Demand Drivers. Energy 40 (2012) 174-188. 